University of Nebraska - Lincoln

DigitalCommons@University of Nebraska - Lincoln

May 2001

\title{
INTERPERSONAL FUNCTIONING AMONG WOMEN REPORTING A HISTORY OF CHILDHOOD SEXUAL ABUSE: EMPIRICAL FINDINGS AND METHODOLOGICAL ISSUES
}

David DiLillo

University of Nebraska-Lincoln, ddilillo@unl.edu

Follow this and additional works at: https://digitalcommons.unl.edu/psychfacpub

Part of the Psychiatry and Psychology Commons

DiLillo, David, "INTERPERSONAL FUNCTIONING AMONG WOMEN REPORTING A HISTORY OF

CHILDHOOD SEXUAL ABUSE: EMPIRICAL FINDINGS AND METHODOLOGICAL ISSUES" (2001). Faculty

Publications, Department of Psychology. 146.

https://digitalcommons.unl.edu/psychfacpub/146

This Article is brought to you for free and open access by the Psychology, Department of at DigitalCommons@University of Nebraska - Lincoln. It has been accepted for inclusion in Faculty Publications, Department of Psychology by an authorized administrator of DigitalCommons@University of Nebraska - Lincoln. 


\title{
INTERPERSONAL FUNCTIONING AMONG WOMEN REPORTING A HISTORY OF CHILDHOOD SEXUAL ABUSE: EMPIRICAL FINDINGS AND METHODOLOGICAL ISSUES
}

\author{
David DiLillo
}

\author{
University of Nebraska-Lincoln
}

\begin{abstract}
A subset of research exploring the long-term impact of child sexual abuse (CSA) has examined the adult interpersonal functioning of female survivors. The present review discusses empirical findings and critical methodological issues related to this important but often overlooked aspect of adult adjustment. Though characterized by several methodological limitations, this literature, as a whole, suggests that early sexual abuse represents a risk factor for a range of interpersonal dysfunction among female survivors, including problems with intimate partner relations, disturbed sexual functioning, and difficulties in the parental role. Suggested methodological improvements for future research include new approaches to the measurement of CSA and interpersonal variables, the need for comprehensive assessment of significant third variables, and the use of more representative sampling strategies.
\end{abstract}

KEY WORDS. Child sexual abuse, Interpersonal, Abuse effects, Social, Maltreatment.

IT WAS NOT long ago that sexual abuse of children was thought to be a relatively rare occurrence in this country. In recent years, however, there has been an increasing realization that childhood sexual abuse (CSA) is endemic to our society. Population surveys estimate that between one fifth and one third of all women in the United States have experienced some form of CSA (Finkelhor, Hotaling, Lewis, \& Smith, 1990; Finkelhor, Moore, Hamby, \& Straus, 1997; Peters, Wyatt, \& Finkelhor, 1986; Russell, 1983). In response to these disturbing figures, a steady stream of research over the past two decades has investigated the possible effects of CSA upon various aspects of women's adult functioning. The bulk of this work, however, has explored the relationship between CSA and individual clinical symptomatology

Correspondence should be addressed to David DiLillo, Department of Psychology, University of Nebraska-Lincoln, 238 Burnett Hall, Lincoln, NE 68588-0308, USA. Fax: (402) 472-4637; Email: ddilillo@un1.edu 
as defined by DSM diagnostic criteria. These efforts have successfully identified CSA as a risk factor for the occurrence of numerous intrapersonal difficulties in adulthood. Depression, anxiety, posttraumatic stress disorder (PTSD), and substance abuse are but a few of the many undesirable outcomes associated with a history of early sexual victimization. Several excellent qualitative reviews have provided thorough summaries of these findings (e.g., Beitchman et al., 1992; Browne \& Finkelhor, 1986; Polusny \& Follette, 1995).

Unfortunately, various indicators point to CSA as a risk factor for problems with adult interpersonal functioning as well. Clinicians have often described pervasive patterns of distress present in the relationships of women reporting a history of child sexual abuse (Courtois, 1988; Kirschner, Kirschner, \& Rappaport, 1993; Maltz \& Holman, 1987; Meiselman, 1990). Consistent with these clinical observations are empirical findings from the PTSD literature documenting impaired interpersonal functioning among survivors of other forms of psychological trauma (Carroll, Rueger, Foy, \& Donahue, 1985; Nadelson, 1989; Resick, Calhoun, Atekeson, \& Ellis, 1981). Finally, several different theoretical conceptualizations, including attachment theory (Alexander, 1992), interpersonal schema theory (Cloitre, 1998), and a contextual behavioral perspective (Polusny \& Follette, 1995) have been advanced as possible explanations for a causal link between CSA and adult interpersonal dysfunction.

Despite clinical impressions, related empirical findings, and various theoretical formulations implicating CSA as a contributor to the development of later interpersonal difficulties, systematic investigation of this relationship has been slow to evolve. When considered at all, interpersonal variables have most often been included within the context of larger studies of the long-term individual correlates of CSA. Nevertheless, these scattered findings have gradually accrued, and together provide a glimpse of the interpersonal functioning among women reporting a history of CSA. Although some previous reviews have included interpersonal outcomes, this diffuse but important body of research has yet to be considered in its entirety. The reciprocal nature of the relationship that exists between individual and social functioning (e.g., depression and marital relations) makes definitive distinctions between the intrapersonal and interpersonal correlates of CSA difficult. For the purposes of this discussion, however, only published studies addressing those consequences of CSA that are inherently interpersonal in nature - those that, by definition, occur in an interpersonal context - will be considered.

\section{METHODOLOGICAL CONSIDERATIONS}

The prototypical methodology utilized to study long-term interpersonal functioning among CSA survivors involves the contemporaneous assessment of childhood sexual experiences and adult interpersonal functioning via self-report in a sample of adult women. Means comparisons or multiple regression analyses are then employed to examine the relationship between sexual abuse status (serving as the IV) and measures of interpersonal functioning (serving as DVs). Although a comprehensive discussion of correlational and retrospective designs in sexual abuse research is beyond the scope of this article (see Briere, 1992), inspection of Table 1, which summarizes major studies in the area, reveals some of the most critical meth- 
odological problems in this area of investigation. These limitations include: (1) inconsistencies in the definitional criteria and methods used to assess child sexual abuse; (2) a failure to consider the role of family of origin functioning and other relevant "third variables" in determining long-term interpersonal difficulties (see Briere, 1988; Nash, Neimeyer, Husley, \& Lambert, 1998), and; (3) a reliance upon unrepresentative sampling techniques. An overview of these methodological issues as they relate to studies of interpersonal functioning among survivors provides a useful framework for understanding the empirical findings to follow.

\section{Measurement Issues}

Because studies of the interpersonal correlates of CSA invariably involve the identification of individuals who have experienced sexual abuse, researchers immediately must contend with the twofold problem of how to first define, and then identify, the presence of CSA in a sample of participants. Regarding the former issue, nearly all studies of interpersonal functioning have dichotomized CSA, classifying participants as having either experienced or not experienced sexual abuse based on a set of criteria established by the investigators. Table 1 reveals the widely divergent definitional criteria that have been employed across studies. Inconsistencies regularly occur in the specific acts determined to be abusive, the upper age limits used to define the term "childhood", and the use of specific age differentials between survivor and offender. Such discrepancies are problematic because they can result in differing estimates of both the prevalence and potential consequences of sexually abusive acts (Haugaard \& Emery, 1989). It might be expected, for example, that more restrictive definitions of sexual abuse would be associated with a greater degree of adult dysfunction. Furthermore, by combining all who report abuse into a single group, investigations have equated victimization experiences that may be qualitatively and quantitatively dissimilar (e.g., the repeated, forcible rape of an 8 year old versus a single incident of fondling). This practice of homogenizing all sexual experiences considered to be abusive hampers the detection of potential variations in outcome as a function of different forms of sexual abuse.

Without exception, investigations have relied upon adults' retrospective reports of childhood sexual experiences as a means of assessing the presence and characteristics of CSA. If, as recent evidence suggests, some adult survivors either do not report actual cases of abuse (Williams, 1994), or report "false memories" of abuse at the time of an investigation (Loftus, 1993), then respondents will inevitably be misclassified. Furthermore, even when legitimate cases of abuse are reported, the simple passage of time may distort recollections of the experience. If some who experienced CSA are assigned to a non-CSA condition and others who were not victimized are classified as abused, these false negatives and false positives will blur distinctions between abused and nonabused participants (Briere, 1992; Polusny \& Follette, 1995).

\section{The Unknown Role of "Third Variables"}

As Briere (1988) and others have noted, in order to infer any direct relationship between sexual abuse experienced during childhood and difficulties with adult interpersonal adjustment, additional factors that may independently contribute to adult relationship dysfunction among survivors must be ruled out as alternative explanations. The negative family circumstances in which many sexually abused children are raised (e.g., high conflict, substance abuse, other 


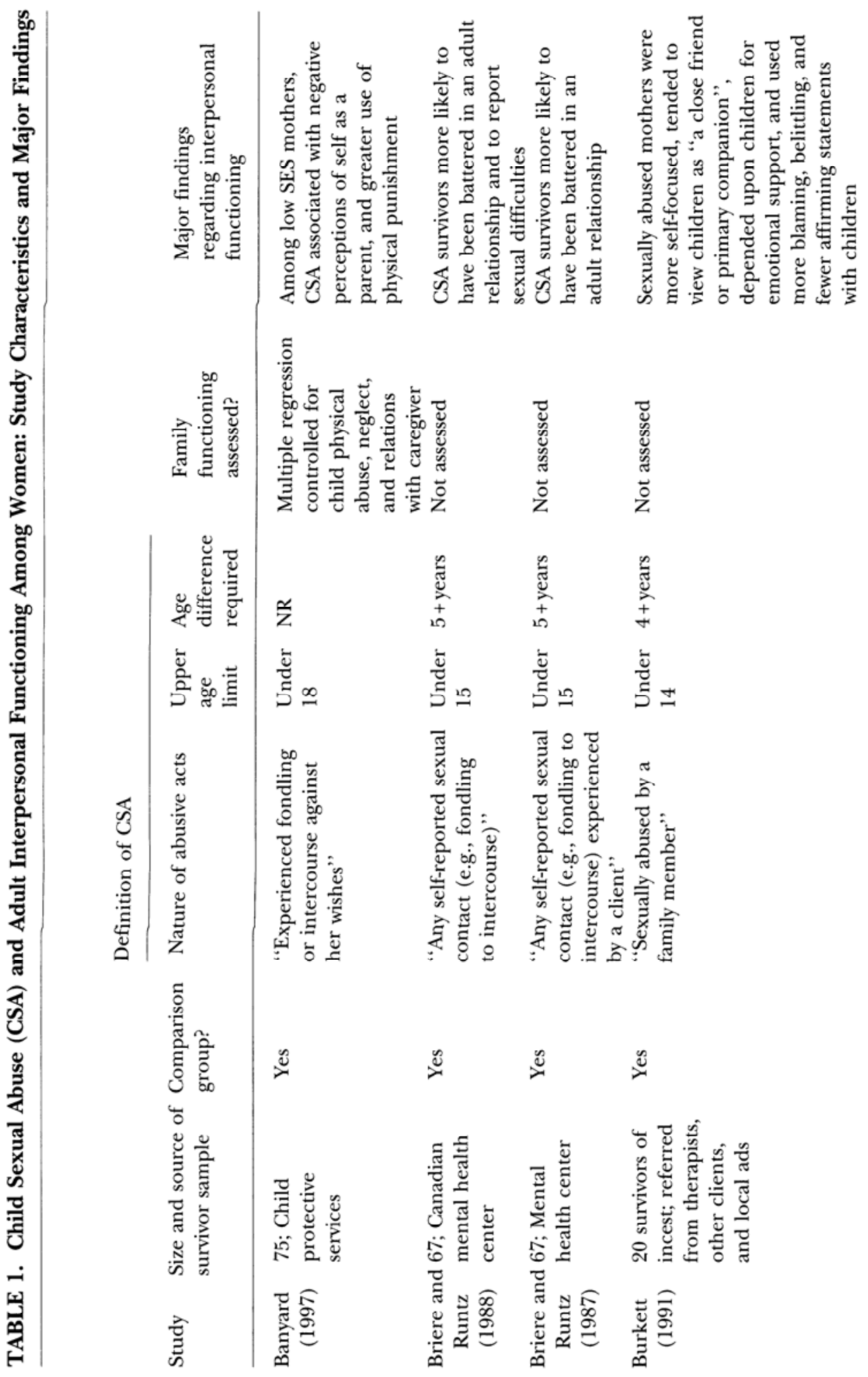



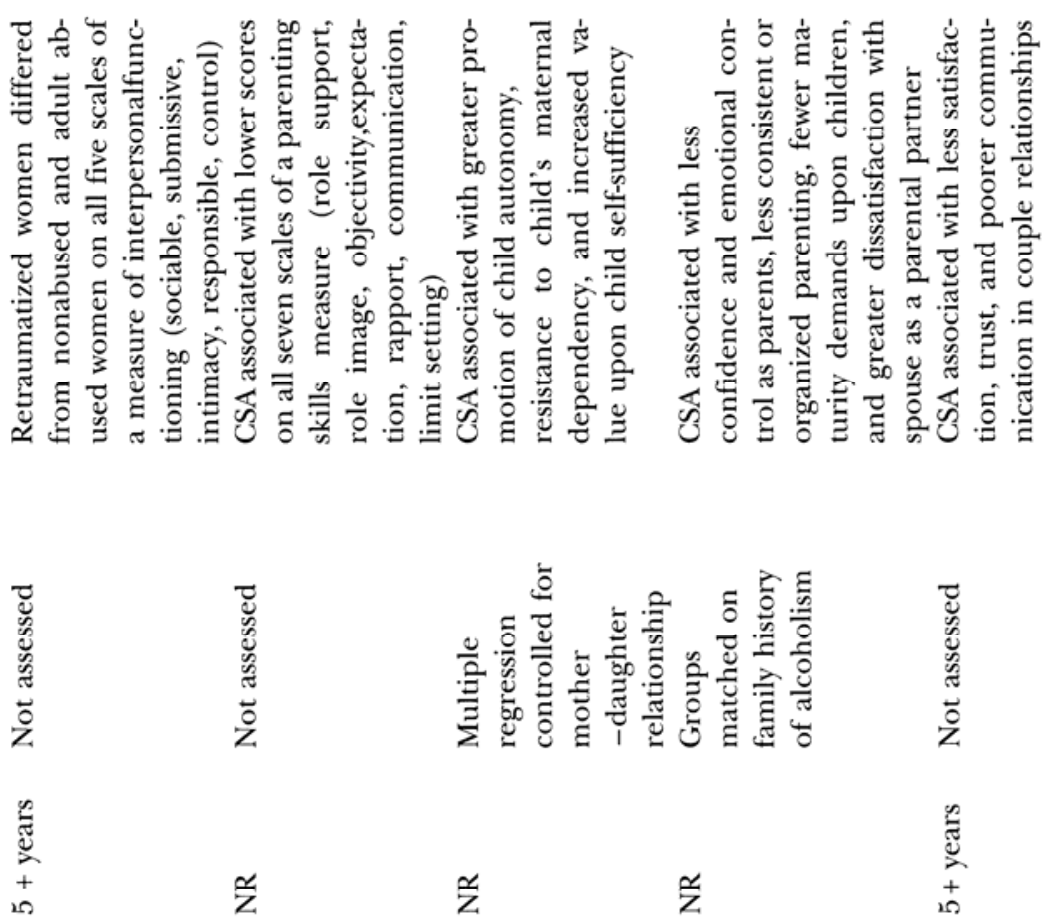



魚

号

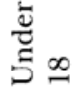

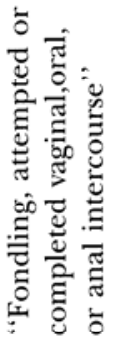

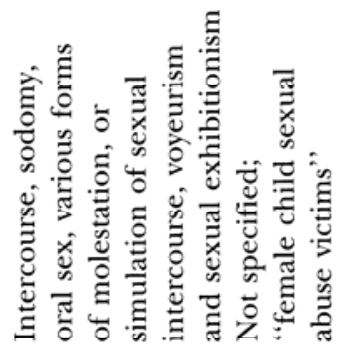

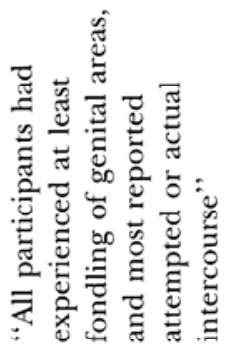

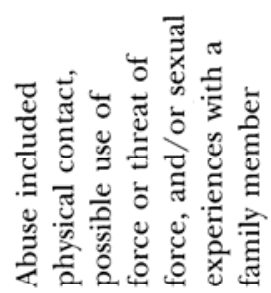



$\stackrel{\sim}{*}$

$\stackrel{\infty}{\infty}$

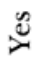

$\stackrel{\varrho}{\succsim}$

ปัँ



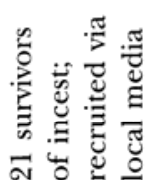



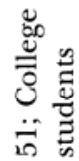

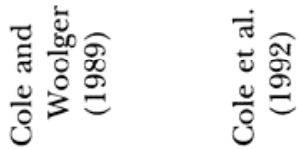

ํㅡㄹํํำ 

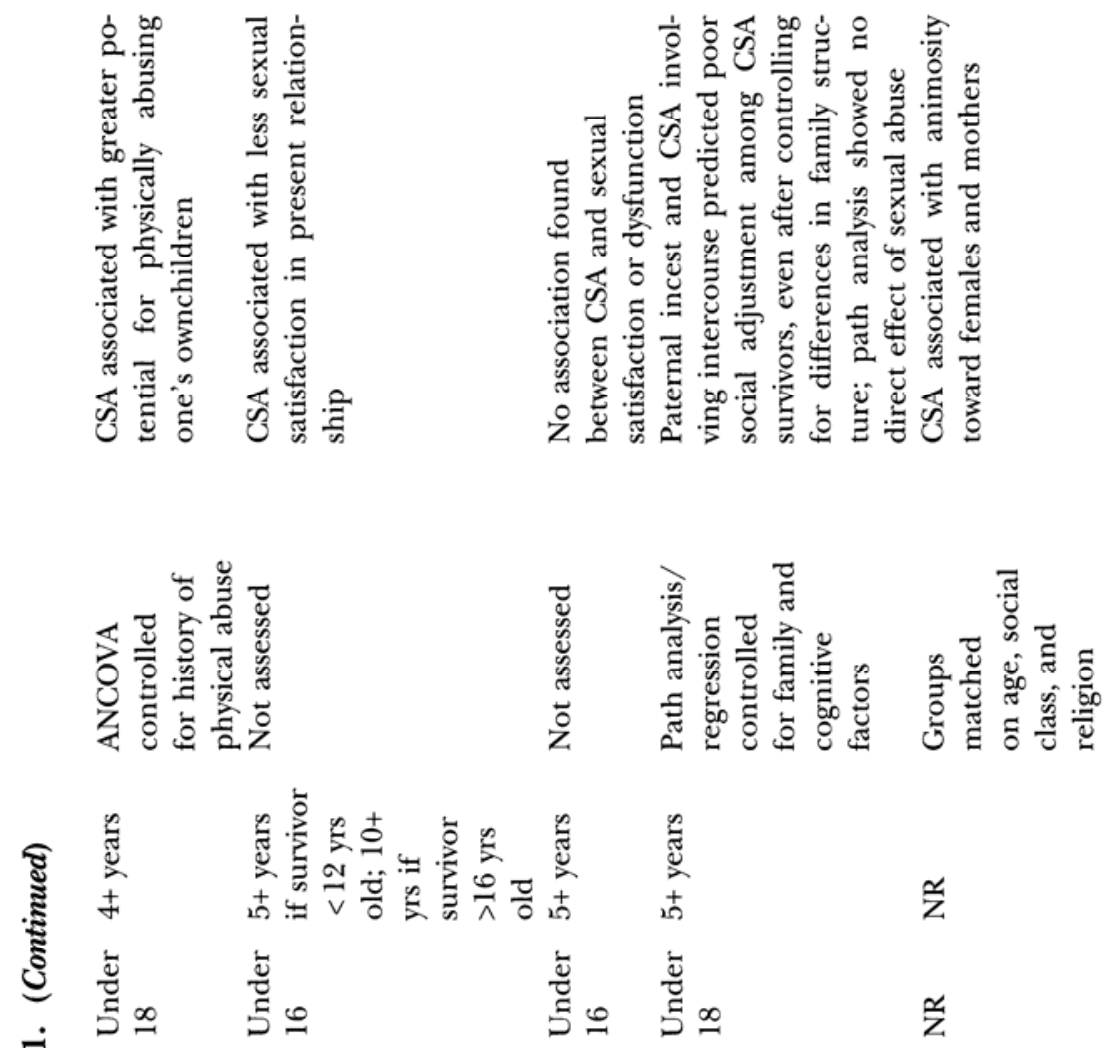

潀
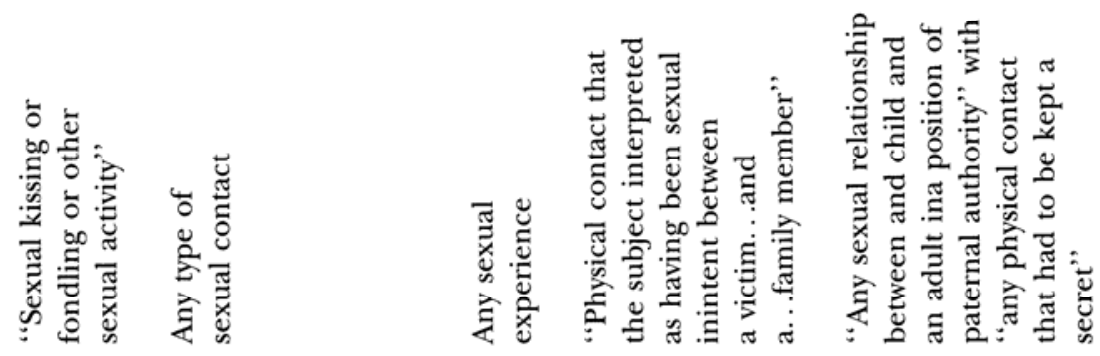



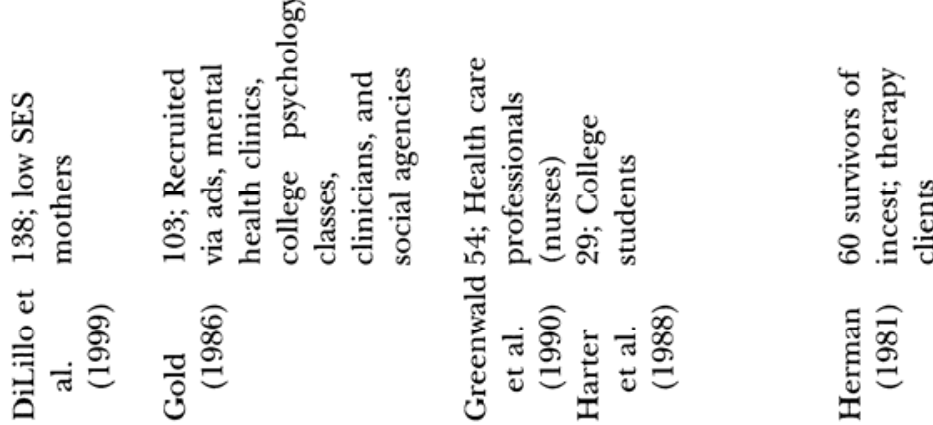


新



气器

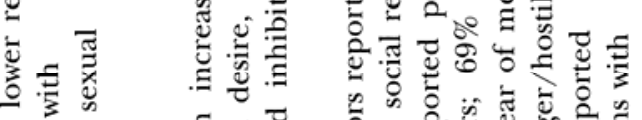

焉

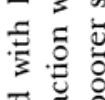

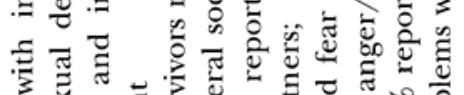

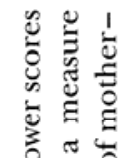

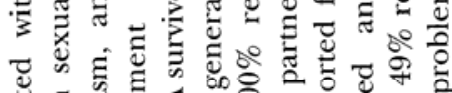



氖管

荧

焉焉

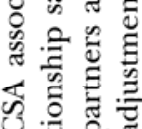

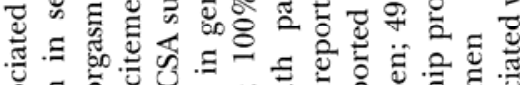

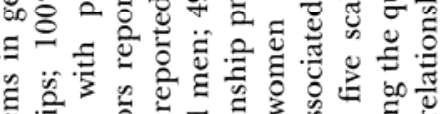

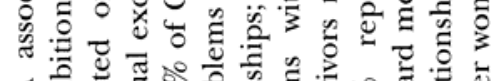

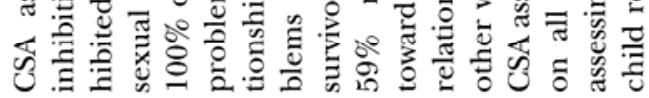

可言产


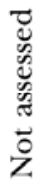



点

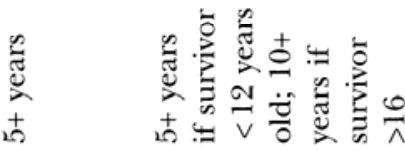

zั

$\stackrel{5}{\tilde{z}} \infty$

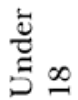



艺

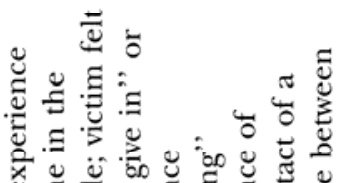

区欠

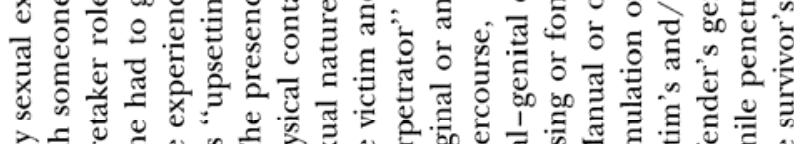


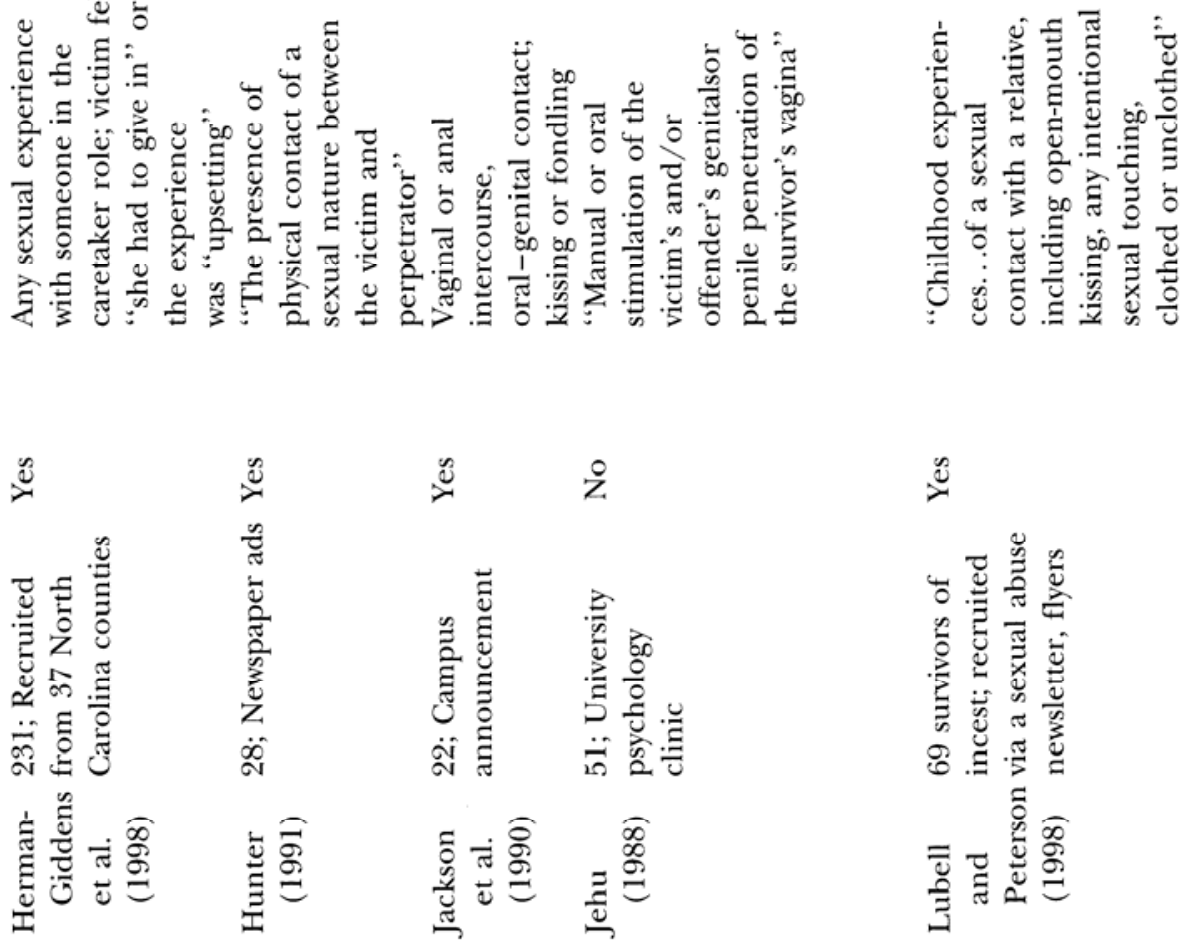

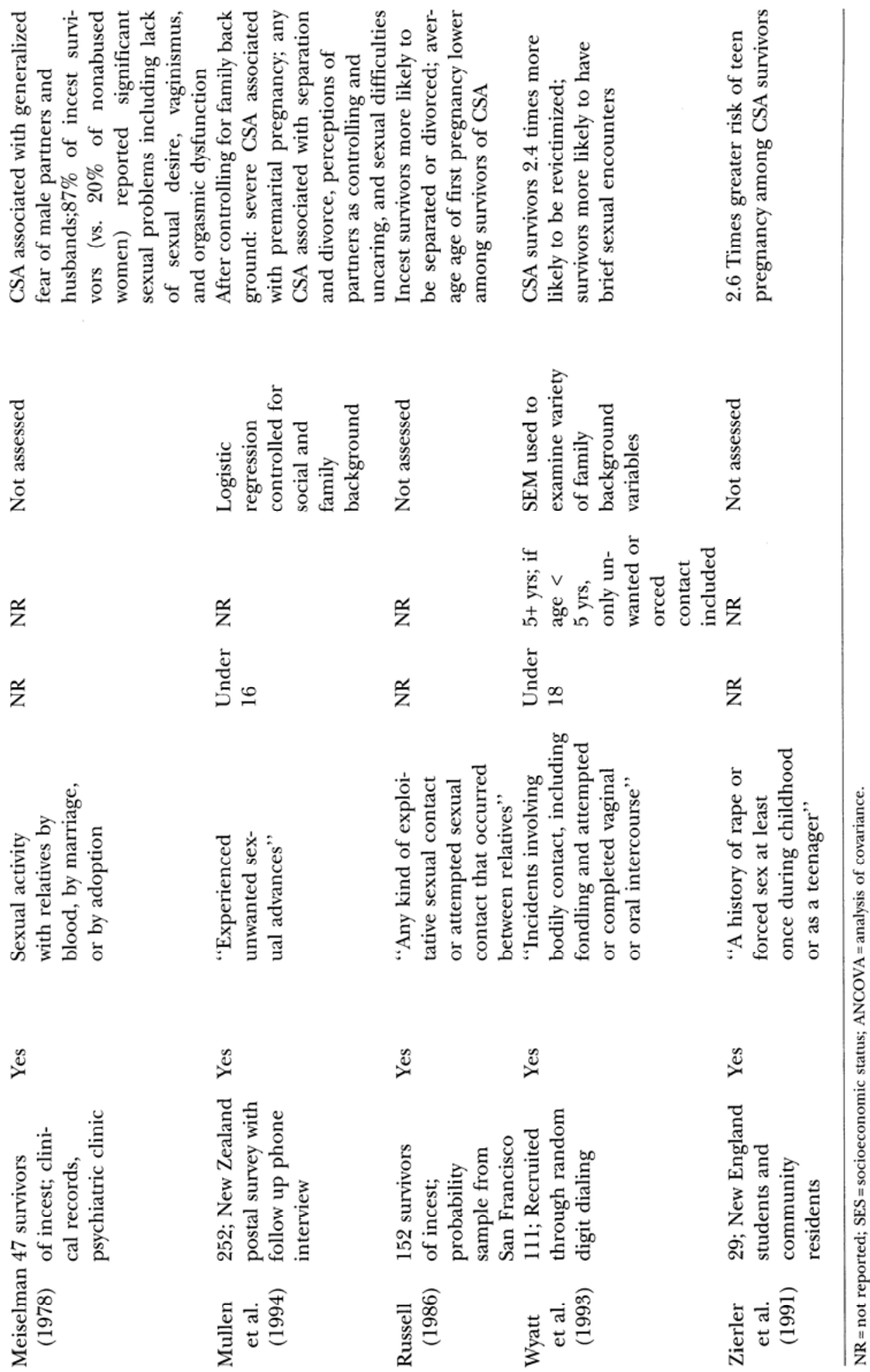
forms of maltreatment) have been cited repeatedly as factors contributing to later symptomatology among individual survivors (Briere \& Elliott, 1993; Nash et al., 1998). In fact, Nash et al. (1998) note that "most researchers have moved away from the magic bullet idea that a specific sexual event invariably leads to a specific outcome or syndrome, instead emphasizing that the psychological effects of abuse must be understood (and studied) within the context of the family-social environment in which it is embedded" (p.568).

To date, however, research on the interpersonal effects of CSA has tended to study sexual abuse in isolation, without attempting to distinguish the potential impact of CSA from the family context in which it occurs. As shown in Table 1, relatively few of the studies covered in this review have attempted to account for the role of third variables, such as family environment. This trend is particularly troublesome in light of findings that the relationship between CSA and later individual psychopathology diminish or disappear altogether when such factors have been statistically controlled (Fromuth, 1986; Harter, Alexander, \& Neimeyer, 1988; Nash, Husley, Sexton, Harralson, \& Lambert, 1993).

\section{Sampling Biases}

Sampling biases have characterized much of the work in this area, as a significant proportion of studies have utilized small samples consisting of college students, individuals who have or are currently undergoing abuse-related psychological treatment, or convenience samples recruited from local communities. In each case, these sampling methods lead to restrictions in the applicability of findings. College students, on average, tend to be younger, may be better adjusted interpersonally, and are less diverse in terms of ethnicity and social class than other abuse survivors; conversely, survivors from clinical settings tend to be less well adjusted and to have experienced more severe forms of abuse than the general population of CSA survivors. Even samples drawn from the community, through advertisements, etc., consist of selfselected individuals who may not adequately represent CSA survivors as a whole.

\section{ADULT INTERPERSONAL FUNCTIONING AMONG FEMALE CSA SURVIVORS}

Despite these methodological caveats, it is important that existing research on the long-term interpersonal adjustment of CSA survivors be reviewed, for it represents the best available information related to this significant realm of functioning. The parameters defining adult interpersonal functioning are quite broad, encompassing survivors' relationships with particular individuals in their lives (e.g., spouses and partners, friends, children, and other family members), as well as the many dimensions upon which those relationships might be impacted by sexual abuse (e.g., communication, trust, intimacy, etc.). Published research on each of these dimensions will be reviewed here.

\section{General Social Adjustment}

Children evaluated within two years of the termination of CSA have been found to be less socially adept and to display more aggression and withdrawal than their nonabused counter- 
parts (Friedrich, Urquiza, \& Beilke, 1986). Studies employing college samples have similarly found poor social/interpersonal adjustment among those with a history of CSA. In one such investigation, the Social Adjustment Scale (SAS; Weissman \& Paykel, 1974) interview was used to compare social functioning in samples of college incest survivors and control subjects (Harter et al., 1988). Although family variables, as well as immediate circumstances surrounding the abuse, were found to make independent contributions to social difficulties, paternal abuse and abuse involving intercourse were predictive of poor social adjustment among survivors, even after controlling for differences in family structure. Using the SAS self-report form (Weissman \& Bothwell, 1976) to assess survivors' interpersonal adjustment in their roles as students, in social and leisure activities, and as a member of a family unit, Jackson, Calhoun, Amick, Maddever, and Habif (1990) found that college-aged incest survivors experienced more social problems in areas such as dating and other leisure-time activities. Problems in several dimensions of interpersonal functioning have been found to distinguish retraumatized women (those experiencing both CSA and adult sexual assault) from women who have been sexually assaulted only as adults, raising the possibility that general interpersonal difficulties may be primarily associated with sexual victimizations occurring during childhood (Cloitre, Scarvalone, \& Difede, 1997).

\section{Couple Relationships}

Couple relationships - a central feature of many people's lives - may be some of the most challenging interpersonal interactions for female survivors. This proposition is supported by consistent evidence of elevated rates of separation and divorce found in community samples of CSA survivors (Finkelhor et al., 1990; Mullen, Martin, Anderson, Romans, \& Herbison, 1994; Russell 1986). Interestingly, however, at the time of the comprehensive review by Browne and Finkelhor (1986), almost no data existed concerning intimate partner relations among survivors. More recently, a small amount of research on this key aspect of interpersonal functioning has emerged.

Satisfaction with male intimate partner relations. Women with a history of sexual abuse are said to experience a set of intensely ambivalent feelings (e.g., disillusionment, mistrust, idealization, devaluation, and hostility) about men in general (Briere, 1996), and compared to nonabused women, survivors may experience less satisfaction in platonic interactions with males (Edwards \& Alexander, 1992). Numerous clinical writings have documented patterns of dysfunction in survivors' marital and couple relationships (Courtois, 1988; Kirschner et al., 1993; Maltz \& Holman, 1987; Meiselman, 1990). Interview data from several studies reveal a general pattern of dissatisfaction with couple relationships, with survivors reporting greater levels of overall marital discord (Jehu, 1988), generalized fear of partners and husbands (Meiselman, 1978), and moderate to severe conflict with partners, including feelings of fear, mistrust, and hostility in their relationships with men (Courtois, 1979). Studies utilizing comparison groups and standardized self-report measures corroborate these observations. Sexually abused female college students have reported lower satisfaction in their committed relationships in comparison to nonabused women (DiLillo \& Long, 1999), as measured by the Quality Marriage Index (QMI; Norton, 1983). Similar results have been found by Hunter (1991) 
from a self-selected community sample using the Dyadic Adjustment Scale (DAS; Spanier, 1976), as well as in a random sample of 2250 New Zealand women who not only reported low satisfaction with their relationships, but also perceptions of high control and low caring on the part of their male partners (Mullen et al., 1994).

Difficulties with interpersonal trust and intimacy may contribute to the general relationship dissatisfaction expressed by survivors. From a developmental perspective, Cole and Putnam (1992) suggest that incest weakens children's capacity for experiencing trust and safety with emotionally significant people, persisting in distrust, insecurity, and suspiciousness in adult relationships. The gross betrayal of trust committed by a perpetrator (often a family member) upon an unsuspecting child has been cited as a contributor to lasting difficulties in the area of interpersonal trust among adult survivors (Courtois, 1988; Finkelhor \& Browne, 1985). Mullen and colleagues' (1994) survey found that women with a history of abuse were significantly more likely than nonabused women to have difficulties confiding in and discussing personal concerns with their male partners. Although trust in this study appears to have been assessed from only a single interview question, more reliable measures also indicate that survivors place significantly less emotional trust in their partners, and have less confidence that significant others can be counted upon to perform important supportive behaviors for them (DiLillo \& Long, 1999).

There is reason to suspect that communication may be another significant aspect of couple functioning negatively impacted by CSA. Butler (1978) refers to a "conspiracy of silence", on both an individual and societal level, that surrounds the occurrence of CSA. The code of silence that often envelopes CSA may engender feelings of stigmatization, shame, and inferiority in survivors (Finkelhor, 1988), thereby stifling the development of optimal (i.e., direct, open, honest) communication patterns between survivors and significant others. Mullen et al. (1994) found that $23 \%$ of survivors reported "no meaningful communication" with their partners, whereas only $6 \%$ of nonabused women said the same. Similarly negative perceptions of communication with partners have also been reported among college women with a history of CSA (DiLillo \& Long, 1999).

Physical or sexual assault by partners. Findings from several sources indicate that CSA is a risk factor for various forms of later-life victimization, either physical or sexual, have recently been the subject of a detailed review (see Messman \& Long, 1996). Part of this phenomenon of revictimization appears to involve physical abuse by male partners. Studies of clinical samples almost invariably find that, compared to nonabused women, survivors are at greater risk of physical mistreatment committed by male partners than are women without such histories (Briere, 1984; Briere \& Runtz, 1987, 1988). Typical of these findings are results reported by Briere and Runtz (1987) that significantly more sexually abused women (49\%) than nonabused women $(18 \%)$ had been battered by their partners. In a large probability sample of women residing in San Francisco, it was found that a greater percentage of adult women abused as children (between $38 \%$ and $48 \%$, depending upon on the severity of their own abuse) than nonabused women (17\%) had physically abusive husbands. Between $40 \%$ and $62 \%$ of these abused women also reported that they had later been sexually assaulted by their husbands, compared with $21 \%$ of nonvictims (Russell, 1986).

Other data also suggest that revictimization in the form of sexual assault committed by individuals known to the survivor may be common. It might be expected, for instance, that many of the sexual assaults experienced by college-aged survivors of CSA occur at the hands 
of a known individual (Gidycz, Hanson, \& Layman, 1995). Indeed, Cloitre et al. (1997) found that $81 \%$ of the adult sexual assaults experienced by revictimized women were perpetrated by a male acquaintance of the survivor. These findings, that CSA survivors experience an increased risk of subsequent assault by partners or other acquaintances, are particularly troublesome, considering that multiple victimizations are associated with increased levels of individual psychopathology and general distress (Follette, Polusny, Bechtle, \& Naugle, 1996). Results such as these suggest the need for dyadic-level interventions.

Partner characteristics. Given the increased risk for revictimization, it is perhaps not surprising that male partners of sexually abused women are frequently characterized as less well adjusted and less supportive in comparison to partners of nonabused women. Survivors' partners have been described as being overly dependent, insecure, immature, and exploitative (Brittain \& Merriam, 1988; Gelinas, 1983; Jehu, 1988). As a group, they are also said to prefer emotional distance in their relationships (Courtois, 1988; Davis, 1991). Gelinas (1983) describes a process of role reversal, in which survivors who are inappropriately placed in a parental role as children continue this pattern into adulthood, where they subordinate their own needs to those of their immature, overly dependent partners. Another damaging, yet more subtle dynamic observed by Follette (1992), involves the problem of "benevolent blame" that can occur in survivors' marriages when a well-meaning partner is outwardly supportive of the survivor, but simultaneously holds her entirely responsible in some way for the couple's marital troubles, thereby perpetuating feelings of shame and stigmatization she may already experience. As noted, survivors themselves have attributed a lack of concern and a tendency to be overcontrolling to their partners (Mullen et al., 1994).

At present, hypotheses about the undesirable personal characteristics of male partners have yet to be supported empirically. The only published investigation to explore this issue is somewhat inconclusive regarding differences between partners of abused and nonabused women. Lambourn-Kavcic and Day (1995) predicted that male partners of incest survivors would report greater tendencies toward dependency and exploitation, as well as a sense of entitlement and greater overall levels of narcissism. Personality measures administered to 30 incest survivor partners and 30 nonincest survivor partners revealed none of the expected differences on these variables. However, power to detect group differences in this study may have been limited by the small sample size. Group differences may also have been diminished by the fact that most of the incest survivor partners had recently participated in therapy or support groups for partners of survivors. Although studies may yet confirm anecdotal observations that female survivors become involved with poorly adjusted men, such generalizations must be considered premature at this time.

\section{Sexual Functioning}

In contrast to the most other aspects of interpersonal adjustment, sexual functioning has received considerable attention in the literature, perhaps because sexual difficulties are often considered to be individual psychiatric problems. Thirty-nine of 42 total odds ratios calculated for a recent review of community studies published since 1990 showed statistically significant relationships between CSA and sexual difficulties during adolescence or adulthood (Ferguson 
\& Mullen, 1999). The authors noted two general patterns in their findings - one suggesting that CSA is related to a variety of high-risk sexual activities, such as an increased frequency and number of sexual relationships, lower usage of risk-reducing contraceptives, and a greater likelihood of participation in commercialized sex and prostitution. The second trend across studies was a strong association between early sexual victimization and behavioral indications of diminished sexual satisfaction, in the form of sexual arousal disorders, inhibited orgasm, and coital pain. These findings are consistent with those of several earlier studies also documenting rather pervasive sexual difficulties among adolescent and adult survivors of sexual abuse (Gold, 1986; Maltz \& Holman, 1987; Meiselman, 1978; Tsai, Feldman-Summers, \& Edgar, 1979). In a rare deviation from this general pattern, one study of 54 women reporting a history of sexual abuse and an equal number of matched controls revealed no group differences with respect to self-reported sexual satisfaction or sexual dysfunction (Greenwald, Leitenberg, Cado, \& Tarran, 1990). However, because of the low return rate of questionnaires (22\% of 1500$)$ these results should be interpreted with caution.

Sexual functioning among survivors has generally been defined in terms of behavioral descriptors thought to be indicative of sexual dysfunction (e.g., frequency of intercourse, number of sexual partners, etc.). With only minor exceptions (e.g., Mullen et al., 1994), less attention has been paid to the more subjective, but clinically relevant, affective and interpersonal aspects of sexual functioning (Mackey et al., 1991). Factors such as survivors' feelings about their own sexuality and communication with partners about sexual matters have rarely been addressed, yet may operate independently of behavioral or physiological descriptors of sexual functioning. The potential confounding influences of relationship satisfaction have also been overlooked in studies of sexual functioning.

\section{Relationships with Other Women}

Female friendships. Given that the vast majority of female survivors are sexually abused by males, it might seem curious to note findings that many incest survivors harbor greater animosity toward other women than toward men. In Herman's (1981) investigation, comparisons were made between 40 father-daughter incest survivors and 20 women with no such history, but whose fathers had behaved seductively toward them (i.e., displayed sexually motivated behaviors devoid of actual physical contact or secrecy). After matching the two groups by age, social class, and religion, interview data showed that incest survivors experienced greater feelings of anger and hostility toward women than toward the actual perpetrator. In fact, this sample of women tended to idealize men. By contrast, the Jehu (1988) clinical sample reported higher rates of anger toward men than women. Nevertheless, nearly half (49\%) of the sample of 51 survivors "disparaged women" and $39 \%$ reported anger toward them.

In a more recent study of survivors' relationships with other adult women, self-identified incest survivors recruited from various victim assistance organizations, and nonvictimized controls, were recruited from local advertisements (Lubell \& Peterson, 1998). Results of standardized self-report measures administered to the two groups revealed that survivors' and nonabused women's female relationships differed in few respects. The groups reported no differences regarding the extent of their friendship networks, conflict resolution abilities, sati- 
sfaction, intimacy, trust, and companionship with other females. A minor exception was a finding that survivors' closest single friendship with a female had lasted an average of 7 years less than those of their nonabused counterparts'.

Relations with mothers. The reports of anger and hostility toward women in general become much more explicable considering that many survivors are said to feel a strong sense of betrayal and resentment toward their mothers for not protecting them from - or even for colluding with -an abusive father or other perpetrator (Courtois, 1988). Female survivors' perceptions of their mothers in Herman's (1981) study ranged from ambivalent at best, to "actively hostile. . .marked by bitterness and contempt" (p. 81). Others have observed that women in clinical samples commonly express feelings of anger toward their mothers (Tsai \& Wagner, 1978), perhaps feeling more hostility toward their maternal caregivers than toward the perpetrator himself (DeYoung, 1982). Some rather consistent evidence of strained maternal relations comes from a study finding that survivors and nonabused women differed across all five subscales of a measure assessing their relationships with their mothers (Lubell \& Peterson, 1998). On this measure, survivor participants reported less satisfaction, less compatibility, less intimacy, more conflict, and less assurance in the continuity of their relationships with their mothers. Compared to nonabused women, survivors also spent less time with their mothers, and would have preferred even less interaction with them than they had.

\section{Parenting}

Child-bearing patterns. As noted, female CSA survivors consistently report engaging in high levels of risky sexual behavior (Fergusson \& Mullen, 1999; Polusny \& Follette, 1995). This trend, combined with initial data linking CSA to an early onset of puberty among some girls (Herman-Giddens, Sandler, \& Friedman, 1988), suggests that altered child-bearing patterns might be common among survivors. Studies examining sexual abuse as a factor in early pregnancy have yielded inconsistent findings. Zierler et al. (1991) found their sample of 29 female CSA survivors to be 2.6 times more likely than a comparison group of 54 nonabused women to become pregnant before the age of 18 . This is consistent with data from a larger probability sample showing that sexually abused females had their first child an average of a year and a half earlier than their nonabused peers (Russell, 1986). It appears, however, that when social and family background variables are considered, the relationship between CSA and early pregnancy is greatly diminished. For example, HermanGiddens, Kotch, Browne, Winsor, and Stewart (1998) reported no differences between abused and nonabused participants in age of first pregnancy once demographic characteristics were controlled. After taking family and social background into account, Mullen et al. (1994) found only the most severe forms of CSA to be predictive of early pregnancy. Abused and nonabused females matched on the basis of age, race, gender, and social class have also been found not to differ on age of pregnancy (Widom \& Kuhns, 1996). Regarding family size, one study indicates that sexually abused mothers may have more children at an early age than do their nonabused counterparts, even after adjustments for demographic differences were made (Herman-Giddens et al., 1998). 
Relations with offspring. Problems in the parenting arena might be expected for several reasons. First, the high rates of dysfunction present in survivors' families of origin may deny them adequate exposure to effective parental models. Second, the abuse experience itself, and its manifestations within individual survivors (e.g., anger, low self-esteem, depression), may undermine survivors' confidence and competencies in their own parenting abilities. Finally, parenting abilities may be hindered by difficulties in other interpersonal domains, such as the marital relationship -a possibility consistent with findings that the quality of mothers' parenting can be mediated by the quality of marital interactions (Crockenberg, 1987).

Mothers with a history of abuse have been found to behave in a more subtly seductive manner and to engage in role reversal more frequently with their children than do nonabused women (Sroufe, Jacobvitz, Mangelsdorf, De Angelo, \& Ward, 1985). Burkett (1991) assessed maternal/survivor-child interactions in a videotaped interaction using the Structural Analysis of Social Behavior, a circumplex model of human behavior based upon interpersonal theory. According to this analysis, sexually abused mothers were more selffocused (as opposed to child-focused) than their nonabused peers in the study. Sexually abused mothers were also more likely to view their children as "a close friend or primary companion," and to depend upon their children for emotional support, again suggesting a pattern of role reversal (Burkett, 1991). Finkelhor and Baron (1986) have noted that failure on the part of survivors to maintain appropriate relationship boundaries with their own children could increase their children's vulnerability to abuse by a male partner, suggesting one potential mechanism for intergenerational transmission of CSA.

Parenting abilities and attitudes. A small amount of research has examined the relationship between CSA and future parenting attitudes and abilities. Cole and Woolger (1989) examined child-rearing attitudes and perceptions of families of origin among 21 mothers who endured incest and 19 mothers with a history of extrafamilial sexual abuse. Incest survivors, particularly those with negative perceptions of their own mothers, tended to place more emphasis upon children's autonomy than did other survivors (endorsing the statement "The earlier a child is weaned from its emotional ties to its parents the better it will handle its own problems"). Incest survivors also resisted their children's dependency upon them, and valued children's self-sufficiency to a greater extent than survivors of nonfamilial sexual abuse. The two groups in this study did not differ in their general attitudes regarding nurturance and control of their children. The same authors later included two comparison conditions - a group of nonabused women whose fathers had been alcoholics, and a "no risk" group of nonabused mothers with no history of family alcoholism -to assess parenting among survivors (Cole, Woolger, Power, \& Smith, 1992). This strategy was intended to control for the high rates of alcoholism observed in sexually abusive homes (Herman, 1981; Russell, 1986). As expected, survivor mothers reported less confidence and emotional control in their roles as parents than did mothers in the no-risk group. No significant differences were found between children of alcoholics and the sexually abused mothers on these dimensions. However, differences between these two groups may have been obscured by the high prevalence of alcoholism in the incest survivors' families of origin. Incest survivors in this study did report normative attitudes regarding nurturance and disciplining of their children.

At least three investigations have found differences between abused and nonabused mothers in the area of parenting skills, as measured by self-report instruments. Cohen (1995) administered the Parenting Skills Inventory (PSI; Nash \& Morrison, 1984) to a clinical sample 
of 26 Israeli CSA survivors and found that abused mothers performed more poorly than 28 nonabused mothers on all seven scales of the measure, particularly those assessing rolesupport, communication, and role image. Among low income mothers, a history of CSA has also been linked to negative perceptions of one's self as a parent, as well as greater use of physical punishment (Banyard, 1997). Finally, low socioeconomic mothers with a history of CSA may also be at an unusually high risk for physically abusing their own children (DiLillo, Tremblay, \& Peterson, 1999), as reflected in elevated scores on the Child Abuse Potential Inventory (CAPI; Milner, 1986).

\section{Summary of Interpersonal Functioning}

In spite of methodological limitations, the fairly consistent pattern of difficulties found across various realms of relationship functioning paints a rather disturbing picture of the interpersonal life of women reporting a history of CSA. In terms of general social competence, for example, there is some indication that female survivors may be less well-adjusted than their nonabused peers, though this relationship appears to weaken after controlling for family environment. CSA also appears to be a predictor of dissatisfaction with intimate partner relations, as evidenced by the increased rates of divorce and separation experienced by survivors. Interpersonal trust and communication may be areas of particular vulnerability for survivors whose relationships are intact. Adult female survivors are at a greater risk of being revictimized, either sexually or physically, in the context of couple relationships. Sexual maladjustment, as indexed by behaviors and physiological descriptors, appears to be a common problem among survivors, though less is known about survivors' affective appraisals of their own sexual functioning. At present, there is little evidence to support the contention that survivors' peer relationships are markedly impaired, although some results have shown survivors' relationships with their own mothers to be strained. Finally, the realm of parenting may pose challenges for female survivors whose self-reports suggest difficulties maintaining appropriate boundaries with children, as well as discomfort with the emotional demands of parenthood. These problems may manifest in impaired skills in some aspects of parenting, or even an increased potential for discipline strategies considered to be physically abusive.

\section{FUTURE RESEARCH DIRECTIONS}

The majority of research assessing CSA outcomes has employed traditional diagnostic nosology. This symptom-oriented approach is useful in classifying the individual mental health problems many survivors ultimately experience, but it does little to explain the developmental pathways through which CSA may operate upon survivors' adult adjustment. Key to understanding this process is a recognition that, like other traumatic experiences, CSA may interfere with normative developmental trajectories in children, disrupting the formation of self-concept and sexual identity, and distorting basic beliefs about trust, safety, and control in relation to emotionally significant people (Cole \& Putnam, 1992; Trickett \& Putnam, 1993). In the absence of some remedial experience, these developmental deficits can set the stage for adult interpersonal dysfunction in the form of poor couple and peer relationships, strained family interactions, and difficulties in the parenting role. 
There is consistent evidence that familial responses and social support following the initial disclosure of abuse serve to aggravate or mitigate the trauma experienced by children (Conte \& Schuerman, 1987; Everson, Hunter, Runyon, Edelsohn, \& Coulter, 1989; Gomes-Schwartz, Horowitz, \& Cardarelli, 1990). As important as these immediate interactions appear to be, the potential for long-term interpersonal functioning to hinder or promote the psychological wellbeing and recovery of adult survivors is largely unknown. Recent findings that a strong marital relationship may buffer against depression among female survivors (Whiffen, Judd, \& Aube, 1999) represent but one illustration of the many ways in which interpersonal and psychological factors can interact to mediate and/or moderate the relationship between CSA and adult psychopathology. Of particular value would be the identification of social factors that may combine to predict the resilience to lasting harm that has been found in a significant proportion of female survivors (Finkelhor, 1990). Detailed knowledge of these relationships can reveal viable targets for therapeutic intervention and behavior change - targets likely to be overlooked by an exclusive focus upon individual symptomatology (Follette, Ruzek, \& Abueg, 1998).

Several aspects of survivors' interpersonal relationships warrant further study. Marital and other dyadic interactions of female CSA survivors are poorly understood at present; knowledge of general dissatisfaction on the part of survivors does little to elucidate the specific relational factors, such as intimacy, trust, communication, power, control, and decision making, that may be impacted by CSA. Moreover, husbands and partners of survivors may experience significant "secondary" responses to CSA, ranging from anger and resentment to feelings of estrangement, isolation, and confusion (Bacon \& Lein, 1996; Brittain \& Merriam, 1988; Chauncey, 1994; Firth, 1997; Jehu, 1988). These reactions suggest the need for dyadic interventions assessing for the presence of vicarious or indirect effects of CSA upon partners. In addition, considering the multiple emotional and physical demands of child rearing, too little has been done to investigate the impact of early sexual abuse upon parenting processes. Recent indications that a maternal history of sexual abuse may be a risk factor for the occurrence of extrafamilial sexual abuse or physical abuse to one's own children (DiLillo et al., 1999; Oates, Tebbutt, Swanston, Lynch, \& O'Toole, 1998) make the need for information about parenting processes even more pressing.

The question of interpersonal processes in psychotherapy with survivors has yet to be explored in any systematic fashion. Kohlenberg and Tsai (1998) have developed a treatment approach uniquely suited to helping individuals with interpersonal difficulties believed to arise from repetitive, abuse-related trauma in childhood. Based upon principles of functional analytic psychotherapy (FAP; Kohlenberg \& Tsai, 1991), this approach holds that the therapeutic relationship can itself serve a reparative function by providing survivors" in vivo opportunities to build in more adaptive interpersonal repertoires that failed to develop due to traumatic early life conditions" (Kohlenberg \& Tsai, 1998, p. 312). Models such as this could serve as a useful framework for evaluating the efficacy of psychotherapy in addressing interpersonal issues among survivors.

\section{RAISING THE BAR: THE NEED FOR IMPROVED METHODOLOGIES}

As with any multiply determined, distal outcome, a high degree of methodological rigor is needed if the intricate relationship between CSA and later interpersonal adjustment is to be 
clearly delineated. This level of rigor has yet to infuse the study of interpersonal functioning among CSA survivors. For a time, when the significance of CSA as a social problem was initially coming to light, looser methodologies may have had utility as a means of quickly illuminating the scope and nature of the problem (Briere, 1992). Currently, however, there is a need to incorporate greater sophistication in the design of studies in this area. The push for improved methodologies will include increased attention to the issues .noted at the outset of this article: (1) difficulties in the measurement of abuse-related and interpersonal outcomes; (2) a failure to account for the role of family environment and other third variables, and; (3) biased sampling procedures. Although these challenges are not foreign to sexual abuse researchers (see discussions by Briere, 1988, 1992; Haugaard \& Emery, 1989; Kilpatrick, 1987), they nevertheless represent a continuing source of difficulty for the field, particularly in investigations of interpersonal outcomes among survivors.

\section{Improved Approaches to Measurement}

The measurement of both abuse-related and interpersonal variables should be more carefully considered in future investigations. Finkelhor (1994) notes that definitional ambiguities in CSA research are bound to persist as long as there is societal debate concerning the specific acts considered to be abusive. Future investigators might strive to use comprehensive criteria, not only to assess CSA, but also to account for other potential sources of trauma, including exposure to natural disasters, stressful medical procedures, accidents, and physical maltreatment; for each, operational definitions should be clearly articulated. Less emphasis on all-or-nothing approaches to defining the term "sexual abuse" could avert some of the problems associated with homogenizing the very diverse experiences that constitute CSA. CSA in its various forms might instead be assessed along a continuum ranging from least to most severe and incorporating salient features of the experience (e.g., intrafamilial versus extrafamilial, relationship to the offender, age of onset and duration of abuse, etc.). This type of classification scheme would also permit within-subjects analyses that are useful in linking specific abuse characteristics to differential outcomes in interpersonal functioning (Briere, 1988).

Retrospective reports provided by adults are likely to remain the primary means of assessing CSA. This is problematic, considering the inherent drawbacks and controversies surrounding the accuracy of such reports. The reliability of retrospective reports of abuse is certainly amenable to investigation, with initial data showing marginal (Fry, Rozewicz, \& Crisp, 1996) to adequate stability of reports over time (Fink, Bernstein, Handelsman, Foote, \& Lovejoy, 1995; Martin, Anderson, Romans, Mullen, \& O'Shea, 1993). In the absence of corroborating data, there is no sure method of determining the validity of adults' recollections of abuse. However, as noted by Fergusson and Mullen (1999), it is possible to gain further insight into the accuracy and limitations of recalled abuse experiences. These authors have suggested several strategies for doing so, which include: (1) further exploration of the extent to which reports of CSA are affected by variations in data collection procedures (i.e., number of screening questions used and context in which they are asked); (2) the use of longitudinal or panel designs to assess the reliability of individuals' reports of abuse across time; and (3) the need for longitudinal studies that follow and assess children known to have been abused, in order to asses the accuracy of recall of abuse over time (Fergusson \& Mullen, 1999). 
Because interpersonal functioning, by definition, involves the interactions of multiple individuals, future studies should include the partners, peers, children, and family members of survivors in studies of interpersonal adjustment, in order to extend observation of these relationships beyond the lens of the survivors' own perceptions. Direct observation of dyadic and family interactions would also provide a useful increment toward objective assessment of relationship functioning.

Assessing the role of third variables. Findings reviewed here show that CSA predicts long-term interpersonal problems in several areas. A fundamental question yet to be answered -one with great therapeutic and policy implications -is whether CSA actually causes the symptomatology with which is has been associated (Briere, 1988). Although causality cannot be ascertained from correlational designs, a significant step forward would result from a determination that CSA is empirically related to interpersonal dysfunction above and beyond the influence of third variables, particularly adverse circumstances occurring in survivors' families of origin. The preferred method of pursuing this goal would be through the use of longitudinal designs, which would allow researchers to trace the evolution of abuse and family variables over time (Briere, 1992). Given the expenses and logistic complexities of prospective studies, there remains a need to determine the best means of accounting for relevant third variables within cross-sectional frameworks.

One common approach to identifying unique variance associated with CSA has been to exert statistical control over significant third variables, such as family functioning, by using a composite score from some broad measure of family functioning as a covariate during analyses (see for example Nash et aI., 1993). Briere and Elliott (1993) urge caution in the use of so-called "partialing" procedures, such as analysis of covariance, in quasiexperimental studies of sexual abuse where the control variables (e.g., family functioning) may not be causally antecedent to the independent variable (CSA). Under such circumstances, partialing techniques may lead to an overestimation of the role of family environment in the development of adult symptomatology (Briere \& Elliott, 1993). Because group membership is predetermined by participants' ex post facto reports of abuse, and because CSA (both intra- and extrafamilial) has the potential to produce family disruption (Courtois, 1988; Manion et al., 1998), partialing procedures may lead to erroneous conclusions about the relative importance of abuse and family factors in predicting adult interpersonal problems (Briere \& Elliott 1993).

Alternative strategies have been suggested for assessing main long-term effects associated with CSA. Briere (1988) proposed the use of simultaneous multiple regression procedures, which permit an examination of the independent contributions of family and CSA variables in predicting interpersonal functioning (though do not resolve the allocation of overlapping variance among predictors). It has also been noted that structural equation modeling (SEM) represents a useful tool in sexual abuse research (Briere, 1992; Polusny \& Follette, 1995). Indeed, theory-driven causal modeling offers a promising approach to help identify the reciprocal influences that may exist between sexual abuse from family context, as well as hypothesized relationships between interpersonal and intrapersonal outcomes associated with CSA.

Improved sampling procedures. While it is true that interpersonal difficulties have been found across varied samples drawn from college, clinical, and community populations, very few studies within a single domain of interpersonal functioning have utilized large enough 
samples to adequately represent the general population of female CSA survivors. The reliance upon relatively small, nonrandom sampling procedures has resulted in serious limitations upon the external validity of results. It has been observed, for example, that ethnic minority groups and older adults have rarely been the focus of sexual abuse research (Polusny \& Follette, 1995). Moreover, larger samples are necessary for the execution of more sophisticated multivariate statistical analyses (Briere \& Elliott, 1993). Collaborative efforts involving the pooling of data sets could facilitate such analyses, and may become increasingly feasible as the field evolves toward more comprehensive assessment strategies.

\section{CONCLUSIONS}

By its very nature, CSA is an intensely interpersonal trauma characterized by extreme physical and psychological boundary violations occurring during a particularly vulnerable period of development. While this alone suggests the possibility of lasting interpersonal difficulties, the body of research investigating this hypothesis remains relatively underdeveloped. Although the majority of available data on this topic is characterized by rather serious methodological shortcomings, it nonetheless points to a consistent link between CSA and various types of adult interpersonal dysfunction, including problems with intimate partner relationships, disturbed sexual functioning, and difficulties in the parental role. The fact that no clear or consistent pattern of interpersonal difficulties among adult survivors has emerged, suggests that sexual abuse is currently best viewed as a risk factor for a range of adult interpersonal problems experienced by women.

In the absence of prospective designs, causal hypotheses about the relationship between CSA and adult interpersonal dysfunction cannot be confirmed. Causal conclusions notwithstanding, well-conceived cross-sectional investigations can be useful in further delineating the characteristics of adult interpersonal functioning that may be impacted by a history of sexual abuse. The most informative of these studies will be those that incorporate large, representative samples, utilize refined strategies for the measurement of CSA and interpersonal functioning, and make empirically and theoretically sound attempts to distinguish between influence of sexual abuse and other developmental factors in determining longterm outcomes among survivors. Ultimately, investigations of this nature can improve our understanding of the interpersonal context in which adult survivors must live and cope with their abuse on a daily basis.

Acknowledgments-The author would like to thank Vicki DiLillo, Victoria Follette, Jennifer Perry, Lizette Peterson, and George Tremblay for their comments on earlier versions of this article.

\section{REFERENCES}

Alexander, P. C. (1992). Application of attachment theory to the study of child sexual abuse. Journal of Consulting and Clinical Psychology, 60, 185-195.

Bacon, B., \& Lein, L. (1996). Living with a female sexual abuse survivor: male partners' perspectives. Journal of Child Sexual Abuse, 5, 1-16. 
Banyard, V. L. (1997). The impact of child sexual abuse and family functioning on four dimensions of women's later parenting. Child Abuse and Neglect, 21, 1095-1107.

Beitchman, J. H., Zucker, K. J., Hood, J. E., DaCosta, G. A., Akman, D., \& Cassavia, E. (1992). A review of the long-term effects of child sexual abuse. Child Abuse and Neglect, 16, 101-118.

Briere, J. (1984). The long-term effects of childhood sexual abuse on later psychological functioning: defining a post-sexual abuse syndrome. Paper presented at the Third National Conference on Sexual Victimization of Children, Washington, DC.

Briere, J. (1988). Controlling for faminly variables in abuse effects research: A critique of the "partialling" approach. Journal of Interpersonal Violence, 3, 80-89.

Briere, J. (1992). Methodological issues in the study of sexual abuse effects. Journal of Consulting and Clinical Psychology, 60, 196-203.

Briere, J. (1996). Therapy for adults molested as children (2nd ed.). New York: Springer Publishing.

Briere, J., \& Elliott, D. M. (1993). Sexual abuse, family environment, and psychological symptoms: on the validity of statistical control. Journal of Consulting and Clinical Psychology, 61, 284-288.

Briere, J., \& Runtz, M. (1987). Post-sexual abuse trauma: data and implications for clinical practice. Journal of Interpersonal Violence, 2, 367- 397.

Briere, J., \& Runtz, M. (1988). Post sexual abuse trauma. In G. E. Wyatt, \& G. J. Powell (Eds.), Lasting effects of child sexual abuse (pp. 85-99). Newbury Park, CA: Sage.

Brittain, D. E., \& Merriam, K. (1988). Groups for significant others of survivors of child sexual abuse. Journal of Interpersonal Violence, 3, 90- 101.

Browne, A., \& Finkelhor, D. (1986). Impact of child sexual abuse: a review of the research. Psychological Bulletin, 99, 66-77.

Burkett, L. P. (1991). Parenting behaviors of women who were sexually abused as children in their families of origin. Family Process, 30, 421-434.

Butler, S. (1978). Conspiracy of silence: the trauma of incest. San Francisco: Volcano Press.

Carroll, E. N., Rueger, D. B., Foy, D. W., \& Donahue, C. P. (1985). Vietnam combat veterans and posttraumatic stress disorder: analysis of marital and cohabitating adjustment. Journal of Abnormal Psychology, 94, 329337.

Chauncey, S. (1994). Emotional concerns and treatment of male partners of female sexual abuse survivors. Social Work, 39, 669-676.

Cloitre, M. (1998). Sexual revictimization: risk factors and prevention. In V. M. Follette, J. 1. Ruzek, \& F. R. Abueg (Eds.), Cognitive-behavioral therapies for trauma (pp. 278-304). New York: The Guilford Press.

Cloitre, M., Scarvalone, P., \& Difede, J. (1997). Posttraumatic stress disorder, self- and interpersonal dysfunction among sexually retraumatized women. Journal of Traumatic Stress, 10, 437-452.

Cohen, T. (1995). Motherhood among incest survivors. Child Abuse and Neglect, 19, 1423 -1429.

Cole, P. M., \& Putnam, F. W. (1992). Effect of incest on self and social functioning: a developmental psychopathological model. Journal of Consulting and Clinical Psychology, 60, 174-183.

Cole, P. M., \& Woolger, C. (1989). Incest survivors: the relation of their perceptions of their parents and their own parenting attitudes. Child Abuse and Neglect, 13, 409-416.

Cole, P. W., Woolger, C., Power, T. G., \& Smith, K. D. (1992). Parenting difficulties among adult survivors of father daughter incest. Child Abuse and Neglect, 16, 239-249.

Conte, J. R., \& Schuerman, J. R. (1987). The effects of sexual abuse on children: a multidimensional view. Journal of Interpersonal Violence, 2, 380-390.

Courtois, C. A. (1979). The incest experience and its aftermath. Survivorology: an International Journal, 4, $337-$ 347.

Courtois, C. A. (1988). Healing the incest wound. New York: W.W. Norton and Company.

Crockenberg, S. (1987). Predictors and correlates of anger toward and positive control of toddlers by adolescent mothers. Child Development, 59, 1273-1285.

Davis, L. (1991). Allies in healing. New York: Harper Collins.

DeYoung, M. (1982). The victimization of children. Jefferson, NC: McFarland.

DiLillo, D., \& Long, P. J. (1999). Perceptions of couple functioning among female survivors of child sexual abuse. Journal of Child Sexual Abuse, 7, 59 -76. 
DiLillo, D., Tremblay, G. C., \& Peterson, L. (2000). Linking childhood sexual abuse and abusive parenting: the mediating role of maternal anger. Child Abuse \& Neglect, 24, 767-779.

Edwards, J. J., \& Alexander, P. C. (1992). The contribution of family background to the long-term adjustment of women sexually abused as children. Journal of Interpersonal Violence, 7, 306- 320.

Everson, M. D., Hunter, W. M., Runyon, D. K., Edelsohn, G. A., \& Coulter, M. L. (1989). Maternal support following disclosure of incest. American Journal of Orthopsychiatry, 59, 197-207.

Fergusson, D. M., \& Mullen, P. E. (1999). Childhood sexual abuse: an evidence based perspective. Thousand Oaks, CA: Sage Publications.

Fink, L. A., Bernstein, D., Handelsman, L., Foote, J., \& Lovejoy, M. (1995). Initial reliability and validity of the childhood trauma interview: a new multidimensional measure of childhood interpersonal trauma. American Journal of Psychiatry, 152, 1329-1335.

Finkelhor, D. (1988). The trauma of child sexual abuse: two models. Journal of Interpersonal Violence, 2, 348366. Finkelhor, D. (1990). Early and long-term effect of child sexual abuse: an update. Professional Psychology: Research and Practice, 21, 325-330.

Finkelhor, D. (1994). Current information on the scope and nature of child sexual abuse. The Future of Children, 4, 31-53.

Finkelhor, D., \& Baron, L. (1986). Risk factors for child sexual abuse. Journal of Interpersonal Violence, 1, 43-71.

Finkelhor, D., \& Browne, A (1985). The traumatic impact of child sexual abuse: a conceptualization. American Journal of Orthopsychiatry, 55, 530-541.

Finkelhor, D., Hotaling, G. T., Lewis, I. A, \& Smith, C. (1990). Sexual abuse in a national survey of adult men and women: prevalence, characteristics and risk factors. Child Abuse and Neglect, 14, 19-28.

Finkelhor, D., Moore, D., Hamby, S. L., \& Straus, M. A (1997). Sexually abused children in a national survey of parents: methodological issues. Child Abuse and Neglect, 21, 1-9.

Firth, M. T. (1997). Male partners of female survivors of child sexual abuse: treatment issues and approaches. Sexual and Marital Therapy, 12, 159-171.

Follette, V. M. (1992). Marital therapy for sexual abuse survivors. In J. Briere (Ed.), Treating victims of sexual abuse (pp. 61-71). San Francisco: Jossey-Bass.

Follette, V. M., Polusny, M. M., Bechtle, A. E., \& Naugle, A E. (1996). Cumulative trauma effects: the impact of child sexual abuse, adult sexual assault, and spouse abuse. Journal of Traumatic Stress, 9, 15-25.

Follette, V. M., Ruzek, J. I., \& Abueg, F. R. (1998). A contextual analysis of trauma: theoretical considerations. In: V. M. Follette, J. I. Ruzek, \& F. R. Abueg (Eds.), Cognitive-behavioral therapies for trauma (pp. 3-14). New York: Guilford Press.

Friedrich, W. N., Urquiza, A. J., \& Beilke, R. L. (1986). Behavior problems in sexually abused young children. Journal of Pediatric Psychology, 11, 47 -57.

Fromuth, M. E. (1986). The relationship of childhood sexual abuse with later psychological and sexual adjustment in a sample of college women. Child Abuse and Neglect, 10, 5-15.

Fry, R. P. W., Rozewicz, L. M., \& Crisp, A H. (1996). Interviewing for sexual abuse: reliability and effect of interviewer gender. Child Abuse and Neglect, 20, 725-729.

Gelinas, D. J. (1983). The persisting negative effects of incest. Psychiatry, 46, 312-332.

Gidycz, C. A, Hanson, K, \& Layman, M. J. (1995). A prospective analysis of the relationships among sexual assault experiences: an extension of previous findings. Psychology of Women Quarterly, 19, 5-29.

Gold, E. R. (1986). Long-term effects of sexual victimization in childhood: an attributional approach. Journal of Consulting and Clinical Psychology, 54, 471-475.

Gomes-Schwartz, B., Horowitz, J. M., \& Cardarelli, A. P. (1990). Child sexual abuse: initial effects. Newbury Park, CA: Sage.

Greenwald, E., Leitenberg, H., Cado, S., \& Tarran, M. J. (1990). Childhood sexual abuse: long-term effects on psychological and sexual functioning in a nonclinical and nonstudent sample of adult women. Child Abuse and Neglect, 14, 503-513.

Harter, S., Alexander, P. C., \& Neimeyer, R. A (1988). Long-term effects of incestuous child abuse in college women: social adjustment, social cognition, and family characteristics. Journal of Consulting and Clinical Psychology, 56, 5-8. 
Haugaard, J. J., \& Emery, R. E. (1989). Methodological issues in child sexual abuse research. Child Abuse and Neglect, 13, 89-100. Herman, J. L. (1981). Father-daughter incest. Cambridge, MA: Harvard University Press.

Herman-Giddens, M. E., Kotch, J. B., Browne, D. C., Ruina, M. B. A., Winsor, J. R., Jung, J., \& Stewart, P. W. (1998). Childbearing patterns in a cohort of women sexually abused as children. Journal of Interpersonal Violence, 13, 504-514.

Herman-Giddens, M. E., Sandler, A. D., \& Friedman, N. E. (1988). Sexual precocity in girls: an association with sexual abuse? American Journal of Diseases of Children, 142, 431-433.

Hunter, J. A. (1991). A comparison of the psychosocial maladjustment of adult males and females sexually abused as children. Journal of Interpersonal Violence, 6, 205-217.

Jackson,]. L., Calhoun, K S., Amick, A. A, Maddever, H. M., \& Habif, V. L. (1990). Young adult women who report childhood intrafamilial sexual abuse: subsequent adjustment. Archives of Sexual Behavior, 19, 211-22L

Jehu, D. (1988). Beyond sexual abuse: therapy with women who were childhood victims. New York: john Wiley and Sons.

Kilpatrick, A C. (1987). Childhood sexual experiences: Problems and issues in studying long-range effects. Journal of Sex Research, 23,173-196.

Kirschner, S., Kirschner, D. A., \& Rappaport, R. L. (1993). Working with adult incest survivors/the healing journey. New York: Brunner/Mazel.

Kohlenberg, R. J., \& Tsai, M. (1991). Functional analytic psychotherapy: creating intense and curative therapeutic relationships. New York: Plenum Press.

Kohlenberg, R. J., \& Tsai, M. (1998). Healing interpersonal trauma with the intimacy of the therapeutic relationship. In V. M. Follette,]. 1. Ruzek, \& F. R. Abueg (Eds.), Cognitive-behavioral therapies for trauma (pp. $305-$ 320). New York: Guilford Press.

Lambourn-Kavcic, B., \& Day, H. D. (1995). Characteristics of male partners of adult female incest survivors. Journal of Contemporary Psychology, 25,387-398.

Loftus, E. F. (1993). The reality of repressed memories. American Psychologist, 48, 518-537.

Lubell, A. K. N., \& Peterson, C. (1998). Female incest survivors: relationships with mothers and female friends. Journal of Interpersonal Violence, 13, 193-205.

Mackey, T. F., Hacker, S. S., Weissfeld, L. A, Ambrose, N. C., Fisher, M. G., \& Zobel, D. L. (1991). Comparative effects of sexual assault on sexual functioning of child sexual abuse survivors and others. Issues in Mental Health Nursing, 12, 89-112.

Maltz, W., \& Holman, B. (1987). Incest and sexuality: a guide to understanding and healing. Lexington, MA: Lexington Books.

Manion, I., Firestone, P., Cloutier, P., Ligezinska, M., Mclntyre,]., \& Ensom, R. (1998). Child extrafamilial sexual abuse: predicting parent and child functioning. Child Abuse and Neglect, 22, 1285-1304.

Martin, J. L., Anderson,]. C., Romans, S. E., Mullen, P. E., \& O'Shea, M. (1993). Asking about child sexual abuse: methodological implications of a two stage survey. Child Abuse and Neglect, 17, 383-392.

Meiselman, K. C. (1978). Incest: a psychological study of causes and effects with treatment recommendations. San Francisco: Jossey-Bass.

Meiselman, K. C. (1990). Resolving the trauma of incest. San Francisco: Jossey-Bass.

Messman, T. L., \& Long, P. J. (1996). Child sexual abuse and its relationship to revictimization in adult women: a review. Clinical Psychology Review, 16, 397-420.

Milner, J. S. (1986). The child abuse potential inventory (2nd ed.). Webster NC: Psytec.

Mullen, P. E., Martin, J. L., Anderson, J. C., Romans, S. E., \& Herbison, G. P. (1994). The effect of child sexual abuse on social, interpersonal, and sexual function in adult life. British Journal of Psychiatry, 165, 35-47.

Nadelson, C. C. (1989). Consequences of rape: clinical and treatment aspects. Psychotherapy and Psychosomatics, 51, 187-192.

Nash, L., \& Morrison, W. L. (1984). Manual for the parenting skill inventory. Seattle, WA: Parenting Press.

Nash, M. R., Husley, T. L., Sexton, M. C., Harralson, T. L., \& Lambert, W. (1993). Long-term sequelae of childhood sexual abuse: perceived family environment, psychopathology, and dissociation. Journal of Consulting and Clinical Psychology, 61, 276-283. 
Nash, M. R., Neimeyer, R. A, Husley, T. L., \& Lambert, W. (1998). Psychopathology associated with sexual abuse: the importance of complimentary design and common ground. Journal of Consulting and Clinical Psychology, 66, 568-57L

Norton, R. (1983). Measuring marital quality: a critical look at the dependent variable. Journal of Marriage and the Family, 45, 141-15L

Oates, R. K., Tebbutt, J., Swanston, H., Lynch, D. L., \& O'Toole, B. 1. (1998). Prior sexual abuse in mothers of sexually abused children. Child Abuse and Neglect, 22, 1113-1118.

Peters, S. D., Wyatt, G. E., \& Finkelhor, D. (1986). Prevalence. In D. Finkelhor, S. Araji, L. Baron, A Browne, S. D. Browne, \& G. E. Wyatt (Eds.), A sourcebook on child sexual abuse (pp. 15-59). Beverly Hills: Sage.

Polusny, M. M., \& Follette, V. M. (1995). Long-term correlates of childhood sexual abuse: theory and empirical findings. Applied and Preventive Psychology, 4, 143-166.

Resick, P. A, Calhoun, K. S., Atekeson, B. M., \& Ellis, E. M. (1981). Social adjustment in victims of sexual assault. Journal of Consulting and Clinical Psychology, 49, 705-712.

Russell, D. E. H. (1983). The incidence and prevalence of intrafamilial and extrafamilial sexual abuse of female children. Child Abuse and Neglect, 7, 133-145.

Russell, D. E. H. (1986). The secret trauma: incest in the lives of girls and women. New York: Basic Books.

Spanier,' G. B. (1976). Measuring dyadic adjustment: new scales for assessing the quality of marriage and similar dyads. Journal of Marriage and the Family, 38, 15-28.

Sroufe, L. A., Jacobvitz, D., Mangelsdorf, S., De Angelo, E., \& Ward, M.]. (1985). Generational boundary dissolution between mothers and their preschool children: a relationship systems approach. Child Development, 56, 317 -325.

Trickett, P. K., \& Putnam, F. W. (1993). Impact of child sexual abuse on females: toward a developmental, psychobiological integration. Psychological Science, 4, 81-87.

Tsai, M., Feldman-Summers, S., \& Edgar, M. (1979). Childhood molestation: variables related to differential impacts on psychosexual functioning in adult women. Journal of Abnormal Psychology, 88, 407-417.

Tsai, M., \& Wagner, N. (1978). Therapy groups for women sexually molested as children. Archives of Sexual Behavior, 7, 417-427.

Weissman, M. M., \& Bothwell, S. (1976). Assessment of social adjustment by patient self-report. Archives of General Psychiatry, 33, 1111-1115.

Weissman, M. M., \& Paykel, E. S. (1974). The depressed woman. Chicago: University of Chicago Press.

Widom, C. S., \& Kuhns, J. B. (1996). Childhood victimization and subsequent risk for promiscuity, prostitution, and teenage pregnancy: a prospective study. American Journal of Public Health, 86, 1607-1612.

Williams, L. M. (1994). Recall of childhood trauma: a prospective study of women's memories of child sexual abuse. Journal of Consulting and Clinical Psychology, 62, 1167-1176.

Zierler, S., Feingold, L., Laufer, D., Velentgas, P., Kantrowitz-Gordon, L., \& Mayer, K. (1991). Adult survivors of childhood sexual abuse and subsequent risk of HIV infection. American Journal of Public Health, 81, $572-$ 575. 